\title{
Early Stage Pancreatic Ductal Adenocarcinoma
}

National Cancer Institute

\section{Source}

National Cancer Institute. Early Stage Pancreatic Ductal Adenocarcinoma. NCI

Thesaurus. Code C158961.

Pancreatic ductal adenocarcinoma that has not spread beyond the pancreas. 